\title{
Multiprobe Fluorescence in situ Hybridization (UroVysion) for the Detection of Urothelial Carcinoma - FISHing for the Right Catch
}

\author{
Lukas Bubendorf \\ Division of Cytopathology, Institute for Pathology, University Hospital Basel, Basel, Switzerland
}

\author{
Key Words \\ Cytology · Urine • Bladder cancer • UroVysion • \\ Fluorescence in situ hybridization $\cdot$ Chromosomes
}

\begin{abstract}
Urinary cytology has a well-established role in the detection and monitoring of urothelial carcinoma. The main strength of cytology is the high specificity for high-grade urothelial carcinoma and carcinoma in situ, but it has a low sensitivity for low-grade, non-invasive tumors. There are several other limitations of cytology. Cytology of the upper urinary tract and after intravesical therapy with bacillus Calmette-Guerin is notoriously difficult to interpret. In addition, there is a poorly defined but commonly used category of atypical cytology of uncertain significance. The UroVysion multiprobe fluorescence in situ hybridization has emerged as a helpful tool to address these limitations. It consists of fluorescently labeled DNA probes to detect increased copy numbers (polysomy) of the chromosomes 3, 7 and 17 and deletion of 9 p21, the site of the P16 tumor suppressor gene. Multiple studies have shown that fluorescence in situ hybridization in voided urine and washing specimens can help in patient management due to its superior sensitivity over cytology in different situations. It can be particularly useful to clarify equivocal cytological findings. However, some aspects remain to be further addressed including cost efficiency, optimal cut-off values and the true performance under real-life conditions.

Copyright $\odot 2011$ S. Karger AG, Basel
\end{abstract}

\section{Introduction}

Bladder cancer is the 6th most frequent cancer in developed countries [1]. Because of long-term survival and the need for lifelong routine monitoring and treatment, the cost per patient with bladder cancer from diagnosis to death is highest of all cancers [2]. The majority (70\%) of bladder cancers are non-muscle invasive (stage pTa, pT1 and carcinoma in situ) [3]. Among these, 70\% are low-grade non-invasive ( $\mathrm{pTa}$ ) tumors that often recur but almost never progress to life-threatening disease [4]. Combined cystoscopy and cytology are the gold standard for diagnosis and follow-up of urothelial carcinoma (UC) [5]. The high specificity for the diagnosis of high-grade UC is an undisputed strength of urinary cytology [6-8]. Cytology is particularly powerful in detecting non-visible carcinoma in situ. However, cytology performs weakly in low-grade UC due to an overlap of cytological features with benign urothelial cells. In addition, there is a commonly used but poorly defined category of atypical cytology that has questionable significance [9-11].

Development and progression of cancer are driven by genetic aberrations such as mutations and chromosome and gene copy number abnormalities. Fluorescence in situ hybridization (FISH) is a robust technique for the detection of chromosome copy number gains (polysomies), gains or amplifications and deletions of DNA loci, and translocations. FISH analysis of cytological specimens has become a standard method to identify chromo-

\section{KARGER}

Fax +41613061234

E-Mail karger@karger.ch

www.karger.com
(C) 2011 S. Karger AG, Basel

$0001-5547 / 11 / 0552-0113 \$ 38.00 / 0$

Accessible online at:

www.karger.com/acy
Correspondence to: Prof. L. Bubendorf

Institute for Pathology, University Hospital Basel

Schönbeinstrasse 40

CH-4031 Basel (Switzerland)

Tel. +41 6126528 51, Fax +41 6126531 94, E-Mail lbubendorf@uhbs.ch 
somal aberrations for diagnostic, prognostic or predictive purposes [12-15]. The multiprobe FISH assay UroVysion (Abbott Molecular Inc., Des Plaines, Ill., USA) for the enumeration of chromosomes 3, 7 and 17 and the locusspecific identifier for the region at 9p21 was developed 10 years ago to overcome the diagnostic limitations of urinary cytology [16]. The 4 probes were selected since increased copy numbers (polysomies) of the chromosomes 3, 7 and 17 had been found to be particularly frequent in bladder cancer. Deletion of 9p21, the site of the tumorsuppressor gene $P 16$, is also common and occurs early in the development of both papillary and flat urothelial neoplasia [17]. Subsequent progression is associated with chromosomal instability leading to aneuploidy with multiple chromosomal aberrations.

\section{UroVysion FISH Analysis: Technical Aspects}

\section{Hybridization and Specimen Type}

DNA FISH probes are labeled with fluorescent molecules and hybridize to pericentromeric regions of individual chromosomes or to selected DNA loci. The signals can then be enumerated under a microscope using appropriate fluorescent filters. UroVysion FISH is applicable to almost all types of cytological specimens such as conventional smears, cytospins or liquid-based specimens (e.g. ThinPrep ${ }^{\circledR}$ or SurePath ${ }^{\circledR}$ ) regardless of fixation type (air-dried versus alcohol-based fixatives). FISH works equally well on unstained and Papanicolaoustained specimens. We prefer hybridizing a Papanicolaou-stained cytospin specimen after confirming that the slide contains the urothelial cells of interest. For more details on the technical protocols of UroVysion testing, refer to the package insert and our previous methodology paper [18].

\section{Scoring FISH Signals}

The scanning technique to enrich abnormal cells rather than analyzing a high number of random cells is suggested for the FISH scoring. This is based on the observation that chromosomal polysomy is strongly associated with morphologic features of the nuclei $[16,19]$. Twentyfive urothelial cells are selected based on nuclear abnormalities including enlargement, irregular borders and patchy nuclear staining with 4'-6-diamidino-2-phenylindole. According to the manufacturer's guidelines, a positive FISH result is defined as the presence of $\geq 4$ morphologically abnormal cells with multiple gains (i.e. $>2$ signals of at least 2 of the 3 chromosomes 3,7 or 17), or a loss

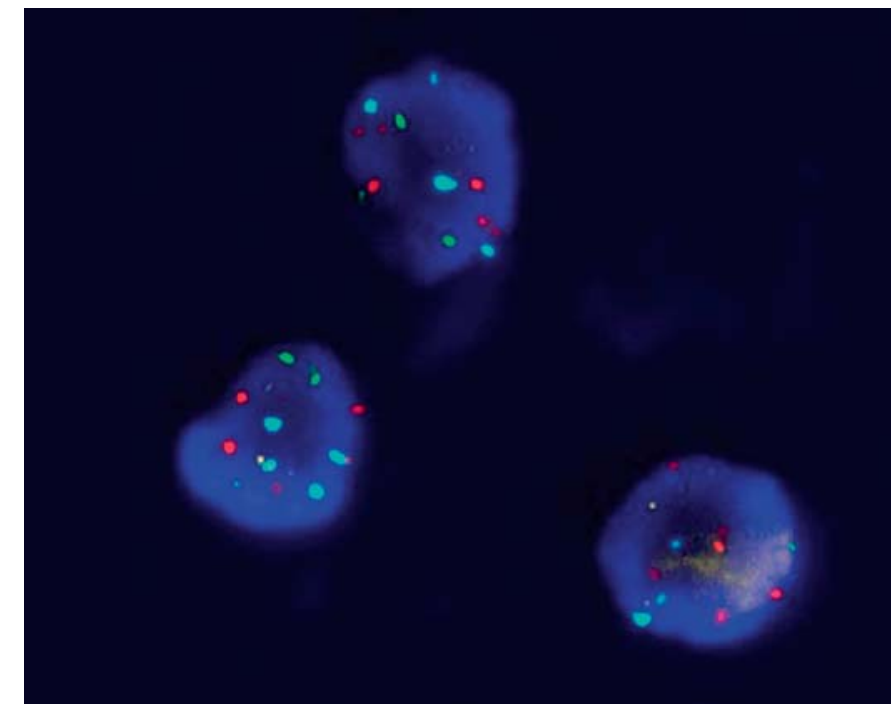

Fig. 1. FISH-positive result of a voided urine specimen: 3 tumor cell nuclei showing increased copy number (polysomy) of the chromosomes 3 (aqua, 4 signals), 7 (spectrum-red, 4-5 signals), but a normal copy number of chromosome 17 (spectrum-green, 2 signals). There is a loss (deletion) of 9p21 (spectrum-gold, $0-1$ signals). $\times 1,000$.

of both copies (homozygous deletion) of 9 p21 in $\geq 12 / 25$ cells (fig. 1). These criteria have proved valid in many studies [20-22]. However, further refinement is possible, and the criteria are evolving. According to Kipp et al. [23], quantitation of FISH abnormal cells by scoring at least 100 cells in every FISH-positive case can provide additional diagnostic information. They found that the percentage of abnormal cells was independently associated with recurrence and progression in patients with a history of non-invasive bladder cancer. The $9 \mathrm{p} 21$ probe also deserves special attention. In addition to homozygous deletion, there are low-grade UC with a heterozygous deletion of 9 p21 as a sole manifestation of malignancy. These cases would be false negative by FISH using the stringent criteria of homozygous deletion in $\geq 12$ cells. Finally, cytologically benign cells can be tetraploid due to transition through the S or G2 phase of the cell cycle or due to endoreplication. Therefore, we recommend to rate the sole presence of rare tetraploid cells (i.e. $\leq 10 / 25)$ in bladder washings as negative $[24,25]$.

\section{Reproducibility}

The reproducibility of UroVysion FISH is poorly investigated. However, Brankley et al. [26] found that reproducibility seems to depend on the percentage of FISH 
abnormal cells. Reproducibility among 7 cytotechnicians was $100 \%$ for 8 specimens with $>10 \%$ abnormal cells, $93 \%$ for 2 negative specimens and lowest (78\%) for 3 specimens with $1-10 \%$ abnormal cells. Thus, it is advisable to confirm FISH-positive results with few abnormal cells (e.g. 5/25 cells) by a second technician and interpret such a borderline result with caution.

\section{Automation}

Automation is not a prerequisite for successful UroVysion FISH scoring but can provide some advantages. The use of a relocation software that drives an automated stage for relocation of individual cells or cell groups is of most practical value and greatly facilitates routine FISH analysis. It allows saving the coordinates of cells of interests that were identified in the Papanicolaou-stained specimen, so that these specific cells can be analyzed for chromosomal aberrations after hybridization. Such relocation also facilitates the review and discussion of FISH findings with the microscope. Notably, this procedure eventually trains the morphology skills of the interpreters as it allows for a direct correlation between cell morphology and chromosomal aberrations. Several imaging systems have been developed for automatic counting of FISH signals. They generate image galleries that need to be edited at the computer screen for the final result. There are currently 2 US Food and Drug Administration-approved systems for automated UroVysion analysis including the Duet System (Bioview Ltd., Rehovoth, Israel, and Billarica, Mass., USA) [27, 28] and the Ikoniscope (Ikonisys Inc., New Haven, Conn., USA) [29]. These systems allow for permanent documentation and retrospective re-analysis of the FISH results. In addition, the Duet System considers both cytomorphology and FISH results for the final diagnosis. The interpretations by the Duet System were equivalent to manual interpretations and lead to modest time savings as compared to manual FISH analysis. Thus, automated FISH analysis systems might be an interesting option for laboratories with a high volume of FISH analyses [28].

\section{Indications and Performance of UroVysion Testing in Urinary Cytology}

The US Food and Drug Administration approved UroVysion testing of voided urine as an aid for initial diagnosis of bladder cancer in patients with hematuria and subsequent monitoring for tumor recurrence in patients previously diagnosed with bladder cancer [30,31]. In rou-
Table 1. Indications for UroVysion FISH analysis in urinary cytology

Atypical urinary cytology

Control after intravesical BCG treatment

Upper urinary tract cytology

Surveillance after transurethral resection

Hematuria in patients with an increased risk of UC

tine practice, there are several additional situations in which FISH is frequently used (table 1). Two recent reviews and a meta-analysis provide detailed summaries on the performance of UroVysion FISH $[22,32,33]$. In the meta-analysis of Hajdinjak [22], the pooled sensitivity and specificity of FISH were 72 and $83 \%$, as compared with 42 and $96 \%$ for cytology. UroVysion FISH has a sensitivity of $90-100 \%$ for the detection of invasive bladder cancer (pT1-4) and a specificity of $>95 \%$ [33]. In the clinically far less relevant category of low-grade non-invasive bladder cancer, FISH increases the sensitivity of cytology from 25 to $60-75 \%$.

Clarification of atypical (or equivocal) cytology has emerged as one of the most rewarding applications of urinary FISH analysis [23, 25, 34-37]. In their pivotal study, Skacel et al. [38] retrospectively evaluated the UroVysion FISH assay in 120 urine specimens and found a sensitivity of 100,89 and $60 \%$ in patients with suspicious, atypical and negative cytology, respectively, while the overall specificity was $97 \%$. A negative test result indicates the presence of benign cytological changes and helps to avoid unnecessary investigations such as repeat cystoscopy or other invasive procedures (fig. 2). A negative FISH result in case of a negative or atypical cytology does not exclude low-grade urothelial neoplasia, since up to $30 \%$ of these tumors are negative with the FISH assay. However, as outlined above, delayed diagnosis of these low-grade urothelial neoplasias is not a major problem, since progression to muscle-invasive cancer is very uncommon. Instead, a negative FISH result makes the diagnosis of a high-grade UC or carcinoma in situ unlikely [25]. Unfortunately, there is no clear morphological definition of the common diagnosis of 'atypical urinary cytology' $[9-11,39]$. Whether a urinary cell is labeled as atypical or equivocal greatly depends on the training, experience and diagnostic confidence of individual observers. There is an obvious need for a uniform classification of urinary cytology as it exists for cervicovaginal cytology and thyroid cytology [40, 41]. A consensus definition of atypical/equivocal urinary cells would boost educational efforts and help to narrow 

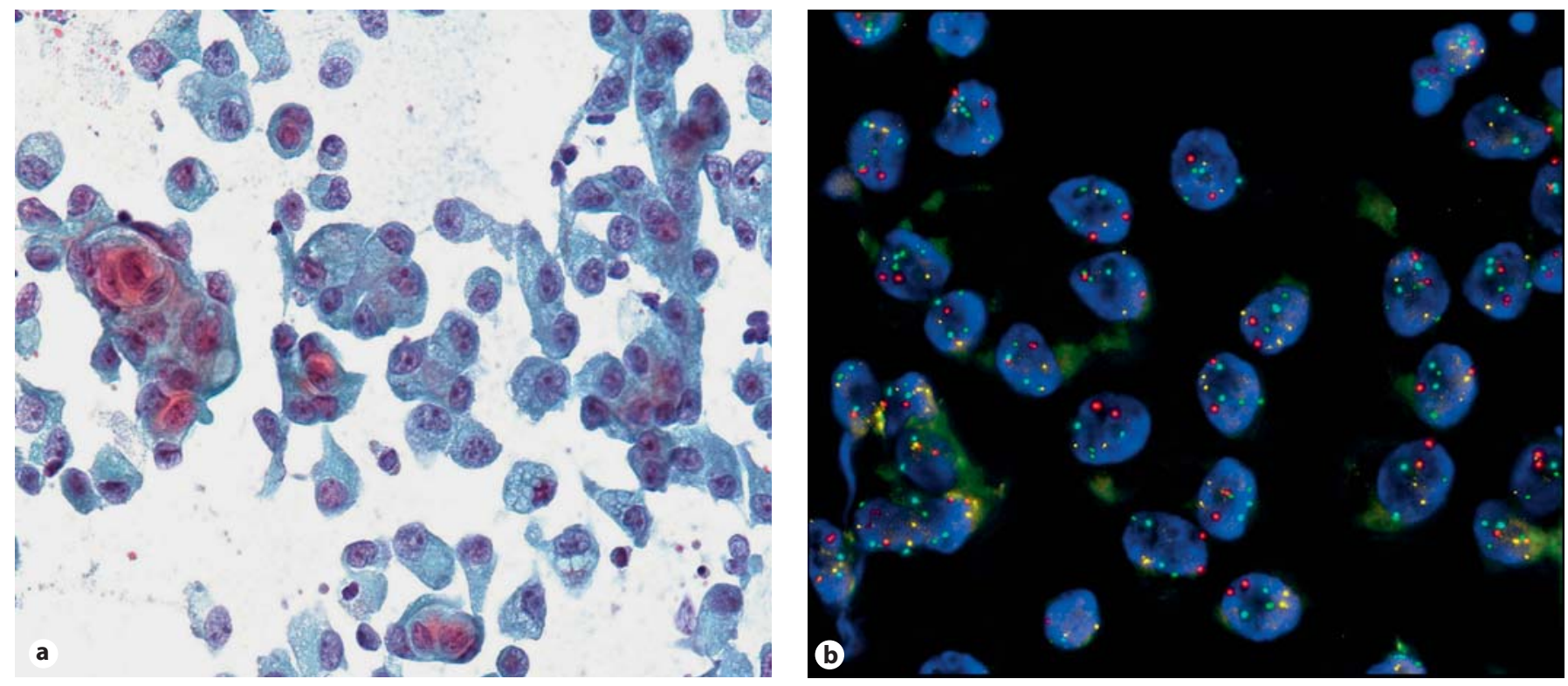

Fig. 2. Cytological atypia in an ureteral washing in favor of reactive changes. a Papanicolaou. $\times 400$. b FISH in the same field after automated relocation showing a negative result with 2 signals for each of the 4 probes in all cell nuclei. $\times 630$.

down indications for reflex FISH testing. To be meaningful, the atypia rate should be kept low.

Cytology after intravesical bacillus Calmette-Guerin (BCG) treatment of high-grade non-muscle invasive UC is notoriously difficult, since the reactive changes can appear most worrisome $[25,42,43]$. We found that patients with a positive post-BCG cytology or FISH result had a 3.2- and 3.8-times higher risk of recurrence, respectively, when compared to the patients with negative results [25]. Kipp et al. [19] and Mengual et al. [44] found a similar impact of FISH after BCG. However, these authors did not consider the impact of cytological diagnosis. In our study, high-grade cytology (G3) retained its high specificity after BCG treatment [25]. A positive FISH result was superior to cytology as a marker of relapse (hazard ratio $=6.2$ and 1.4, respectively) when positive G3 cytology was excluded from the analysis. Two other recent studies confirmed that a positive FISH result in BCG-treated patients with a history of high-grade non-muscle-invasive UC predicts relapse independently of cytology and cystoscopy results $[43,45]$.

In patients under surveillance after a previously resected non-muscle-invasive UC, FISH at the time of a negative cystoscopy can help to better estimate the risk of recurrence $[24,30,37,46]$ although this was not confirmed in all studies $[47,48]$. A positive FISH result at the time of a negative cystoscopy in patients with a sub- sequent recurrence has been referred to as an 'anticipatory' positive FISH result. Notably, this 'anticipatory' quality is not restricted to FISH but can also be achieved by cytology [24]. It has been known for long by cytologists that a positive cytology bears important information irrespective of the cystoscopy or biopsy findings at the time of analysis $[6,49]$. If confirmed in prospective trials, a combination of FISH and cytology might allow to better tailor the schedules of control cystoscopies according to the individual risk, and ultimately, reduce the number of cystoscopies in patients with a low-risk profile.

UC of the upper urinary tract (UUT) is rather uncommon and accounts for only $5 \%$ of urothelial tumors [50]. They are often diagnosed at a high stage, emphasizing the need for an early diagnosis. The sensitivity of cytology is often $<50 \%$ in voided urines, while it is higher in ureteral and pelvic washings [51]. However, interpretation of UUT washing cytologies can be difficult due to instrumentation-related changes and lead to false-positive results. There are several published studies on the value of FISH for the detection of UC of the UUT [52-58]. In voided urines, sensitivity and specificity of FISH ranged from 54-86 to $78-100 \%$ as compared to cytology, which ranged from $24-40$ to $96-100 \%$. In a prospective study on UUT washing cytologies from 55 patients, the overall sensitivity was only $21 \%$ for cytology but $100 \%$ for FISH [55]. The 
specificity was $97 \%$ for cytology and $90 \%$ for FISH. In summary, FISH appears to be an interesting tool to increase the sensitivity for the detection of UC of the UUT. However, the low specificities of 63 and $78 \%$ in 2 of the studies raise concerns about the possibility of false-positive results due to reactive conditions [53].

\section{Pitfall: Chromosomal Abnormalities in Benign Cells}

Chromosomal abnormalities are not restricted to malignancy but can also occur in benign cells. In particular, tetraploidy with a balanced duplication of the whole genome can prevail in non-neoplastic conditions of the bladder [59]. Most of these cells can easily be diagnosed as activated umbrella cells by those trained in cytology. Part of the limited specificity of FISH in some studies might be referable to the overinterpretation of benign tetraploid cells. Therefore, FISH should not be diagnosed as positive, solely based on cells with a tetraploid pattern unless these cells are numerous. Tetraploidy in benign urothelial cells can be explained by a transition status through the S or G2 phase of the cell cycle or by endoreplication as a response to cellular stress [60]. In contrast, unbalanced numerical changes of 1 or more chromosomes (e.g. 2, 3, 5) or loss of 9p21 is virtually specific for neoplasia in bladder cytology. Notably, pelvic irradiation (e.g. of prostate cancer) often leads to permanent chromosomal aberrations, emphasizing the need of appropriate clinical information and consideration of the typical post-irradiation cytomorphological changes. Despite the radiation-induced chromosomal aberrations, the risk of bladder cancer after irradiation for prostate cancer is only marginally increased [61]. In contrast to unbalanced polysomies, we have never observed deletions of 9 p21 in post-irradiation specimens from patients without a history of UC cancer. Thus, a positive FISH result in a patient with a history of pelvic irradiation (e.g. of prostate cancer) does not prove cancer unless there is unequivocal 9p21 deletion.

\section{Controversies and Criticism}

There are ongoing controversies and opinions against a wide application of UroVysion in routine practice $[8,62$, 63]. Some experts emphasize the high accuracy of cytology in detecting high-grade lesions as compared to the minor benefit gained from better diagnosis of clinically harmless low-grade lesions by FISH. There are also concerns about the cost efficiency of the relatively expensive UroVysion testing. The issue of the low-positive predictive value of FISH if applied in unselected patients with hematuria is also stressed $[8,33,62]$. Renshaw [63] questions the reproducibility in actual clinical practice. $\mathrm{He}$ suggests educational programs focusing on borderline or difficult urine cytology and UroVysion samples to provide a basis for evidence-based decisions concerning the best use of these tests in the real-life setting. Taken together, there are valid arguments speaking against a wide and unselected application of UroVysion testing including the comparatively low-positive predictive value in some situations, the limited clinical value of enhanced detection of low-grade UC at a high price, and general concerns about cost efficiency. Nevertheless, the majority of studies and our daily experience suggest that UroVysion FISH can be an excellent diagnostic tool to overcome the limitations of cytology. However, FISH needs to be used wisely in well-defined situations.

\section{Conclusion}

The existing data and our experience suggest that multiprobe FISH is a helpful tool for improved diagnosis in difficult fields of urinary cytology. However, FISH analysis should be performed by persons with experience in cytopathology and not be delegated to purely technical staff. The FISH results must be interpreted in consideration of the clinical findings. Finally, UroVysion FISH is most rewarding in atypical cytological findings but redundant in clearly positive high-grade cytology.
References
1 Parkin DM: The global burden of urinary bladder cancer. Scand J Urol Nephrol Suppl 2008:12-20.

-2 Botteman MF, Pashos CL, Redaelli A, Laskin B, Hauser R: The health economics of bladder cancer: a comprehensive review of the published literature. Pharmacoeconomics 2003;21:1315-1330.

\footnotetext{
3 Kaufman DS, Shipley WU, Feldman AS: Bladder cancer. Lancet 2009;374:239-249.

-4 van Rhijn BW, Burger M, Lotan Y, Solsona E, Stief CG, Sylvester RJ, Witjes JA, Zlotta AR: Recurrence and progression of disease in non-muscle-invasive bladder cancer: from epidemiology to treatment strategy. Eur Urol 2009;56:430-442.
} 
5 Babjuk M, Oosterlinck W, Sylvester R, Kaasinen E, Bohle A, Palou-Redorta J: EAU guidelines on non-muscle-invasive urothelial carcinoma of the bladder. Eur Urol 2008; 54:303-314.

-6 Koss LG, Deitch D, Ramanathan R, Sherman $A B$ : Diagnostic value of cytology of voided urine. Acta Cytol 1985;29:810-816.

7 Renshaw AA: Compassionate conservatism in urinary cytology. Diagn Cytopathol 2000; 22:137-138.

8 Murphy WM: What's the trouble with cytology? J Urol 2006;176:2343-2346.

$\rightarrow 9$ Renshaw AA: Subclassifying atypical urinary cytology specimens. Cancer 2000;90: 222-229.

10 Piaton E, Advenier AS, Bubendorf L: Atypical urothelial cells in the urine. Ann Pathol 2010;30:121-122.

- 11 Brimo F, Vollmer RT, Case B, Aprikian A, Kassouf W, Auger M: Accuracy of urine cytology and the significance of an atypical category. Am J Clin Pathol 2009;132:785793.

12 Jiang F, Katz RL: Use of interphase fluorescence in situ hybridization as a powerful diagnostic tool in cytology. Diagn Mol Pathol 2002;11:47-57.

-13 Oliveira AM, French CA: Applications of fluorescence in situ hybridization in cytopathology: a review. Acta Cytol 2005;49:587594.

14 Savic S, Bubendorf L: Fluorescence in situ hybridization. A new diagnostic dimension in cytology. Pathologe 2007;28:384-392.

15 Halling KC, Kipp BR: Fluorescence in situ hybridization in diagnostic cytology. Hum Pathol 2007;38:1137-1144.

-16 Sokolova I, Halling KC, Jenkins RB, Burkhardt HB, Meyer RG, Seelig SA, King $\mathrm{W}$ : The development of a multitarget, multicolor fluoroescence in situ hybridization assay for the detection of urothelial carcinoma in urine. J Molec Diagn 2000;2:116-123.

-17 Knowles MA: Bladder cancer subtypes defined by genomic alterations. Scand J Urol Nephrol Suppl 2008:116-130.

18 Bubendorf L, Grilli B: UroVysion multiprobe FISH in urinary cytology. Methods Mol Med 2004;97:117-131.

19 Kipp BR, Fritcher EG, del Rosario KM, Stevens CL, Sebo TJ, Halling KC: A systematic approach to identifying urothelial cells likely to be polysomic by fluorescence in situ hybridization. Anal Quant Cytol Histol 2005; 27:317-322.

20 Halling KC, King W, Sokolova IA, Meyer RG, Burkhardt HM, Halling AC, Cheville JC, Sebo TJ, Ramakumar S, Stewart CS, Pankratz S, O’Kane DJ, Seelig SA, Lieber MM, Jenkins RB: A comparison of cytology and fluorescence in situ hybridization for the detection of urothelial carcinoma. J Urol 2000 164:1768-1775.
21 Bubendorf L, Grilli B, Sauter G, Mihatsch MJ, Gasser TC, Dalquen P: Multiprobe FISH for enhanced detection of bladder cancer in voided urine specimens and bladder washings. Am J Clin Pathol 2001;116:79-86.

22 Hajdinjak T: UroVysion FISH test for detecting urothelial cancers: meta-analysis of diagnostic accuracy and comparison with urinary cytology testing. Urol Oncol 2008;26: 646-651.

-23 Kipp BR, Tanasescu M, Else TA, Bryant SC, Karnes RJ, Sebo TJ, Halling KC: Quantitative fluorescence in situ hybridization and its ability to predict bladder cancer recurrence and progression to muscle-invasive bladder cancer. J Mol Diagn 2009;11:148-154.

24 Zellweger T, Benz G, Cathomas G, Mihatsch MJ, Sulser T, Gasser TC, Bubendorf L: Multitarget fluorescence in situ hybridization in bladder washings for prediction of recurrent bladder cancer. Int J Cancer 2006;119:16601665.

25 Savic S, Zlobec I, Thalmann GN, Engeler D, Schmauss M, Lehmann K, Mattarelli G, Eichenberger $\mathrm{T}$, Dalquen $\mathrm{P}$, Spieler $\mathrm{P}$, Schoenegg R, Gasser TC, Sulser T, Forster T, Zellweger T, Casella R, Bubendorf L: The prognostic value of cytology and fluorescence in situ hybridization in the follow-up of nonmuscle-invasive bladder cancer after intravesical bacillus Calmette-Guerin therapy. Int J Cancer 2009;124:2899-2904.

26 Brankley SM, Adams EJ, Christensen MR, Everts CR, Lund JD, Oberg TN, Plagge AM, Zieman AH, Kipp BR, Halling KC: A study of the reproducibility of a fluorescence in situ hybridization bladder cancer detection assay. Anal Quant Cytol Histol 2008;30:145151.

27 Daniely M, Rona R, Kaplan T, Olsfanger S, Elboim L, Freiberger A, Lew S, Leibovitch I: Combined morphologic and fluorescence in situ hybridization analysis of voided urine samples for the detection and follow-up of bladder cancer in patients with benign urine cytology. Cancer 2007;111:517-524.

28 Smith GD, Bentz JS: 'FISHing' to detect urinary and other cancers: validation of an imaging system to aid in interpretation. Cancer Cytopathol 2010;118:56-64.

29 Ntouroupi TG, Ashraf SQ, McGregor SB, Turney BW, Seppo A, Kim Y, Wang X, Kilpatrick MW, Tsipouras P, Tafas T, Bodmer WF: Detection of circulating tumour cells in peripheral blood with an automated scanning fluorescence microscope. Br J Cancer 2008;99:789-795.

30 Sarosdy MF, Schellhammer P, Bokinsky G, Kahn P, Chao R, Yore L, Zadra J, Burzon D, Osher G, Bridge JA, Anderson S, Johansson SL, Lieber M, Soloway M, Flom K: Clinical evaluation of a multi-target fluorescent in situ hybridization assay for detection of bladder cancer. J Urol 2002;168:1950-1954.
31 Sarosdy MF, Kahn PR, Ziffer MD, Love WR, Barkin J, Abara EO, Jansz K, Bridge JA, Johansson SL, Persons DL, Gibson JS: Use of a multitarget fluorescence in situ hybridization assay to diagnose bladder cancer in patients with hematuria. J Urol 2006; 176:44-47.

32 Caraway NP, Katz RL: A review on the current state of urine cytology emphasizing the role of fluorescence in situ hybridization as an adjunct to diagnosis. Cancer Cytopathol 2010;118:175-183.

33 Halling KC, Kipp BR: Bladder cancer detection using FISH (UroVysion assay). Adv Anat Pathol 2008;15:279-286.

34 Glatz K, Willi N, Glatz D, Barascud A, Grilli B, Herzog M, Dalquen P, Feichter G, Gasser TC, Sulser T, Bubendorf L: An international telecytologic quiz on urinary cytology reveals educational deficits and absence of a commonly used classification system. Am J Clin Pathol 2006;126:294-301.

- 35 Kipp BR, Halling KC, Campion MB, Wendel AJ, Karnes RJ, Zhang J, Sebo TJ: Assessing the value of reflex fluorescence in situ hybridization testing in the diagnosis of bladder cancer when routine urine cytological examination is equivocal. J Urol 2008; 179 : 1296-1301.

- 36 Lotan Y, Bensalah K, Ruddell T, Shariat SF, Sagalowsky AI, Ashfaq R: Prospective evaluation of the clinical usefulness of reflex fluorescence in situ hybridization assay in patients with atypical cytology for the detection of urothelial carcinoma of the bladder. J Urol 2008; 179:2164-2169.

-37 Schlomer BJ, Ho R, Sagalowsky A, Ashfaq R, Lotan Y: Prospective validation of the clinical usefulness of reflex fluorescence in situ hybridization assay in patients with atypical cytology for the detection of urothelial carcinoma of the bladder. J Urol 2010;183:62-67.

38 Skacel M, Fahmy M, Brainard JA, Pettay JD, Biscotti CV, Liou LS, Procop GW, Jones JS, Ulchaker J, Zippe CD, Tubbs RR: Multitarget fluorescence in situ hybridization assay detects transitional cell carcinoma in the majority of patients with bladder cancer and atypical or negative urine cytology. J Urol 2003;169:2101-2105.

-39 Kapur U, Venkataraman G, Wojcik EM: Diagnostic significance of 'atypia' in instrumented versus voided urine specimens. Cancer 2008;114:270-274.

40 Solomon D, Davey D, Kurman R, Moriarty A, O'Connor D, Prey M, Raab S, Sherman M, Wilbur D, Wright T Jr, Young N: The 2001 Bethesda System: terminology for reporting results of cervical cytology. JAMA 2002;287: 2114-2119.

41 Ali SZ: Thyroid cytopathology: bethesda and beyond. Acta Cytol 2011;55:4-12.

42 Kipp BR, Karnes RJ, Brankley SM, Harwood AR, Pankratz VS, Sebo TJ, Blute MM, Lieber MM, Zincke H, Halling KC: Monitoring intravesical therapy for superficial bladder cancer using fluorescence in situ hybridization. J Urol 2005;173:401-404. 
43 Fritsche HM, Burger M, Dietmaier W, Denzinger S, Bach E, Otto W, Doblinger $\mathrm{M}$, Schwarz S, Buchner H, Hartmann A: Multicolor FISH (UroVysion) facilitates follow-up of patients with high-grade urothelial carcinoma of the bladder. Am J Clin Pathol 2010; 134:597-603.

-44 Mengual L, Marin-Aguilera M, Ribal MJ, Burset M, Villavicencio H, Oliver A, Alcaraz A: Clinical utility of fluorescent in situ hybridization for the surveillance of bladder cancer patients treated with bacillus Calmette-Guerin therapy. Eur Urol 2007;52: 752-759.

45 Whitson J, Berry A, Carroll P, Konety B: A multicolour fluorescence in situ hybridization test predicts recurrence in patients with high-risk superficial bladder tumours undergoing intravesical therapy. BJU Int 2009; 104:336-339.

-46 Gudjonsson S, Isfoss BL, Hansson K, Domanski AM, Warenholt J, Soller W, Lundberg LM, Liedberg F, Grabe M, Mansson W: The value of the UroVysion assay for surveillance of non-muscle-invasive bladder cancer. Eur Urol 2008;54:402-408.

-47 Karnwal A, Venegas R, Shuch B, Bassett J, Rajfer J, Reznichek R: The role of fluorescence in situ hybridization assay for surveillance of non-muscle invasive bladder cancer. Can J Urol 2010;17:5077-5081.

48 Youssef RF, Schlomer BJ, Ho R, Sagalowsky AI, Ashfaq R, Lotan Y: Role of fluorescence in situ hybridization in bladder cancer surveillance of patients with negative cytology. Urol Oncol 2010, Epub ahead of print.
49 Parwani AV, Levi AW, Epstein JI, Ali SZ: Urinary bladder biopsy with denuded mucosa: denuding cystitis-cytopathologic correlates. Diagn Cytopathol 2004;30:297-300.

50 Gupta R, Paner GP, Amin MB: Neoplasms of the upper urinary tract: a review with focus on urothelial carcinoma of the pelvicalyceal system and aspects related to its diagnosis and reporting. Adv Anat Pathol 2008;15: 127-139.

51 Oosterlinck W, Solsona E, van der Meijden AP, Sylvester R, Bohle A, Rintala E, Lobel B: EAU guidelines on diagnosis and treatment of upper urinary tract transitional cell carcinoma. Eur Urol 2004;46:147-154.

52 Akkad T, Brunner A, Pallwein L, Gozzi C, Bartsch G, Mikuz G, Steiner H, Verdorfer I: Fluorescence in situ hybridization for detecting upper urinary tract tumors - a preliminary report. Urology 2007;70:753-757.

53 Chen AA, Grasso M: Is there a role for FISH in the management and surveillance of patients with upper tract transitional-cell carcinoma? J Endourol 2008;22:1371-1374.

54 Luo B, Li W, Deng CH, Zheng FF, Sun XZ, Wang DH, Dai YP: Utility of fluorescence in situ hybridization in the diagnosis of upper urinary tract urothelial carcinoma. Cancer Genet Cytogenet 2009;189:93-97.

55 Mian C, Mazzoleni G, Vikoler S, Martini T, Knuchel-Clark R, Zaak D, Lazica A, Roth S, Mian M, Pycha A: Fluorescence in situ hybridisation in the diagnosis of upper urinary tract tumours. Eur Urol 2010;58:288-292.
6 Johannes JR, Nelson E, Bibbo M, Bagley DH: Voided urine fluorescence in situ hybridization testing for upper tract urothelial carcinoma surveillance. J Urol 2010;184:879-882.

57 Marin-Aguilera M, Mengual L, Ribal MJ, Musquera M, Ars E, Villavicencio H, Algaba F, Alcaraz A: Utility of fluorescence in situ hybridization as a non-invasive technique in the diagnosis of upper urinary tract urothelial carcinoma. Eur Urol 2007;51:409-415.

58 Shan Z, Wu P, Zheng S, Tan W, Zhou H, Zuo Y, Qi H, Zhang P, Peng H, Wang Y: Evaluation of upper urinary tract tumors by FISH in Chinese patients. Cancer Genet Cytogenet 2010;203:238-246.

59 Wojcik EM, Brownlie RJ, Bassler TJ, Miller MC: Superficial urothelial (umbrella) cells. A potential cause of abnormal DNA ploidy results in urine specimens. Anal Quant $\mathrm{Cy}$ tol Histol 2000;22:411-415.

60 Lee HO, Davidson JM, Duronio RJ: Endoreplication: polyploidy with purpose. Genes Dev 2009;23:2461-2477.

-61 Chrouser K, Leibovich B, Bergstralh E, Zincke $\mathrm{H}$, Blute M: Bladder cancer risk following primary and adjuvant external beam radiation for prostate cancer. J Urol 2005; 174:107-110.

62 Nieder AM, Soloway MS, Herr HW: Should we abandon the FISH test? Eur Urol 2007;51: 1469-1471.

63 Renshaw AA: UroVysion, urine cytology, and the College of American Pathologists: where should we go from here? Arch Pathol Lab Med 2010;134:1106-1107. 